\title{
Procedural sedation and analgesia practices by emergency physicians in the Netherlands: a nationwide survey
}

\author{
Maybritt I. Kuypers ${ }^{1,6^{*}}$, Gaël J. P. Smits ${ }^{2}$, Suzanne C. Valkenet ${ }^{3}$, Wendy A. M. H. Thijssen ${ }^{4}$ and Frans B. Plötz ${ }^{5}$
}

\begin{abstract}
Background: Several efforts have been made to assure and to improve the quality of procedural sedation and analgesia (PSA) performed by emergency physicians (EPs) in The Netherlands. This study investigated the current PSA practice and competences of EPs in both adult and paediatric patients. In particular, if residency and current training, awareness of guidelines is sufficient for registered EPS to adequately perform PSA and if the availability of both adult and paediatric PSA in the ED is adequate.

Methods: A cross-sectional nationwide survey was performed amongst Dutch EPs $(n=463)$ in June 2016. We collected data on background, training, practice, and competencies of both adult and paediatric PSA. We investigated guideline adherence, reasons for not performing PSA, and desired improvements.

Results: The respondents $(n=191)$ represented $84.6 \%$ hospitals with EPs and $41.3 \%$ of all EPs in The Netherlands. Nearly all EPs (97.8\%) performed PSA in adult patients compared to only $59.1 \%$ who performed PSA in paediatric patients $(p<0.001)$. The major reason for not performing paediatric PSA was caused by a lack of exposure during the training-program (74.1\%). PSA-guideline knowledge (98.3\%) and PSA related adverse event registration (98.3\%) were excellent. Lack of 24/7-availability of both adult and paediatric emergency department PSA was mainly caused by a shortage of EPs. Self-reflection indicated that EPs feel less competent in performing paediatric PSA when compared to adult PSA.

Conclusion: This nationwide survey demonstrates that there is still a significant gap between the performance of adult and paediatric PSA even though guideline adherence and registration of PSA-related adverse events appear to be adequate. Enhancement of paediatric PSA training in combination with an increase of EP-staffing can help improve the availability of adult and paediatric PSA in the emergency department.
\end{abstract}

Keywords: Sedation, Analgesia, Emergency medicine, Training, Paediatric and adult

\section{Background}

Procedural sedation and analgesia (PSA) is defined as a technique of administering sedatives or dissociative agents with or without analgesics to induce a state that allows the patient to tolerate unpleasant procedures while maintaining cardiorespiratory function. PSA is an integral part of emergency medicine (EM) practice and can be performed safely and effectively

\footnotetext{
*Correspondence: m.i.kuypers@amc.uva.nl

${ }^{1}$ Academic Medical Centre/ University of Amsterdam, Amsterdam, The Netherlands

${ }^{6}$ Tergooi Hosptial, Hilversum, The Netherlands

Full list of author information is available at the end of the article
}

in adult and paediatric patients in the emergency department (ED) by trained emergency physicians (EPs) [1-5]. PSA delivered in the ED by EPs provides many advantages for both the patient and hospital, like reduced waiting times, reduced operating room and anaesthesia usage, reduced hospital admissions, and considerable savings [6].

In The Netherlands, the first 3-year EM training program commenced in 2000. PSA was introduced in 2005 by EP faculty from the USA [7]. Since then, multiple efforts have been made to assure and to improve the quality of PSA performed by EPs [8]. In 
2012, a national guideline on PSA was implemented [9]. Simultaneously, the Netherlands Society of Emergency Physicians (NSEP) distributed a guideline on emergency PSA, including an updated standard data collection form, intended to aid proper registration and guideline adherence [10]. Organized registration of adverse events due to PSA was made mandatory and used as a quality marker. Following in 2012, NSEP developed a PSA training course and examination, mandatory for all EPs performing PSA in the ED. A survey amongst EM residents in 2013 showed that $45.7 \%$ deemed themselves competent in performing PSA [11]. Since December 2014, PSA has become fully integrated into the national EM curriculum, including a mandatory national PSA qualification examination and clinical evaluation of PSA in practice. It remains unclear, however, the effect of all these measures on current practice of PSA by registered EPs in The Netherlands. This is important because evaluation provides valuable feedback on the design and the implementation of the program.

The aim of this survey study was to investigate the current PSA practice and competences of Dutch EPs in both adult and paediatric patients. In particular, if residency and current training, awareness of guidelines is sufficient for registered EPs to adequately perform PSA and if the availability of both adult and paediatric PSA in the ED is adequate.

\section{Methods}

\section{Study design and setting and participants}

The STROBE statement was used in the design of this study [12]. Approval for this study was obtained through the Scientific Review Committee of the Tergooi Hospital. The committee granted further review board exemption. No patient data was included in this study.

Two authors created the survey (MK, SV). Thereafter, the scientific committee of NSEP piloted the survey. After approval of the survey, NSEP provided access to the list of all registered EPs. In June 2016, an online survey was distributed via email to all registered EPs. Only EPs currently working in a Dutch ED were included for participation. Participation was on a voluntary basis and confidentiality and anonymity were guaranteed to avoid potential participation bias. After 1 week, a reminder was sent to the non-responders.

\section{Variables and measurements}

Data on general and demographic information, experience and practice of PSA in both adult and paediatric patients, residency and current PSA training, guideline use and indicators, and finally PSA-related competencies were collected by use of a digital questionnaire (Additional file 1). Briefly, questions regarding general and demographic data were open or multiple-choice. Most questions related to PSA training and to PSA practice were initially dichotomous and then followed by multiple-option answers. In order to quantify the performance rate, we choose for multiple-choice questions. Questions regarding the technical aspects of the PSA performance were evaluated using the national guideline as a reference standard. To measure the clinicians' opinions or attitudes regarding the adult and paediatric PSA-related competencies, we used a five-point Likert scale to indicate the amount of agreement (strongly agree, agree, neutral, disagree, strongly disagree).

\section{Analysis}

Statistical analysis was performed using IBM SPSS Statistics, Version 22.0. Armonk, NY: IBM Corp.

Group differences between PSA in adults and paediatric patients were analysed for nominal/ordinal variables by chi-square test and for continuous variables by one-sample $t$ test or Mann-Whitney $U$ test where appropriate. Multivariate linear regression was applied to examine the differences in PSA competencies in adults and in paediatric patients, adjusted for demographic variables. All tests were two-tailed. A $p$ value of less than 0.05 was considered to be statistically significant.

\section{Results \\ Participants}

According to NSEP, in June 2016, there were 463 registered EPs in The Netherlands and the survey was accessed by $41.3 \%$ (191/463). Ten respondents did not complete the survey and were therefore excluded from further analysis, leaving 181 responses for analysis. In The Netherlands, there are 87 EDs, of which 65 have at least one EP working in their ED. The respondents represented 55/65 (84.6\%) of the Dutch hospitals with EPs.

\section{Descriptive data}

The majority of the respondents were female (65.7\%). The mode for the respondents' age group was 35-39 years (37.0\%). A small majority had an EP-registration of less than 5 years $(52.8 \%)$. All but one respondent completed their EM training in The Netherlands. The mode for clinical working hours per week was 25-36 h (73.5\%).

\section{Current practice of adult versus paediatric PSA in the ED}

The current practices of adult PSA, including indications for PSA and medication used are displayed in Table 1. PSA in adult emergency patients was performed by $97.8 \%(177 / 181)$ of the EPs, whereas in paediatric patients this was $59.1 \%(107 / 181)(p<0.001)$. PSA was performed in the adult population with a frequency of at least once per week by $53.7 \%(95 / 177)$ of the EPs, and 
Table 1 PSA practice in adults versus paediatric ED patients in The Netherlands

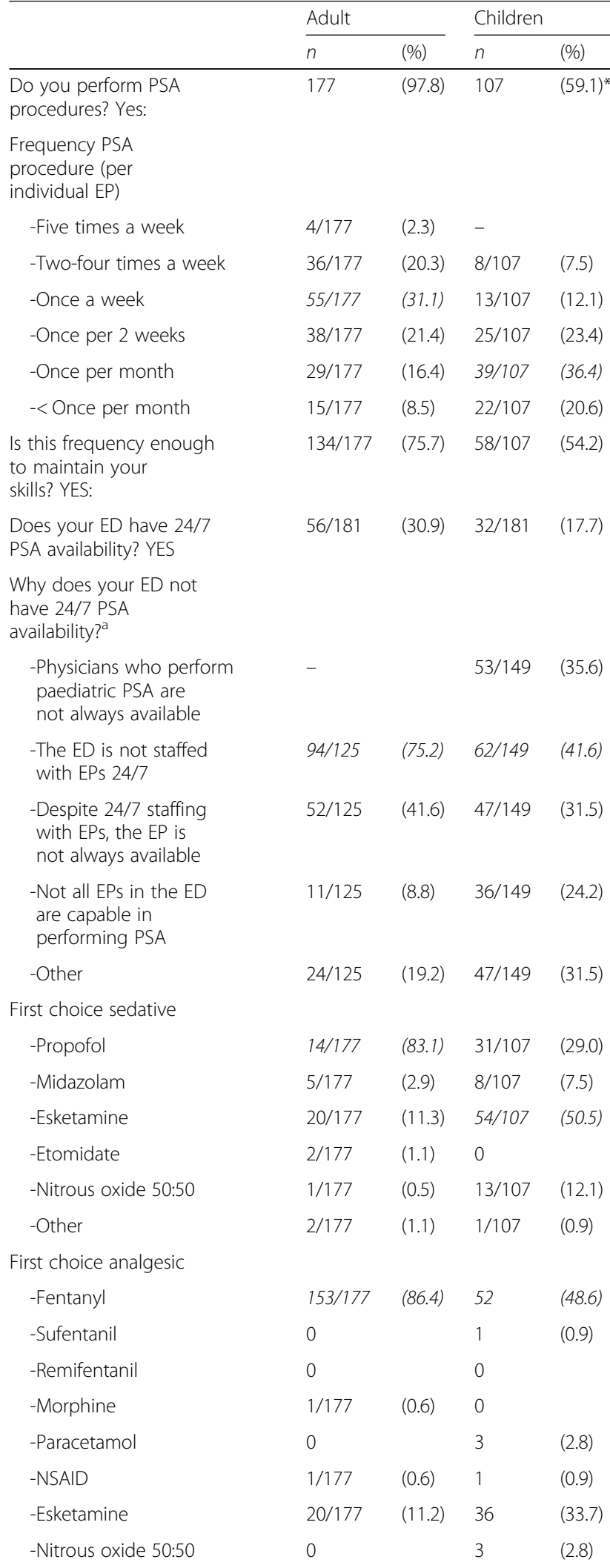

Table 1 PSA practice in adults versus paediatric ED patients in The Netherlands (Continued)

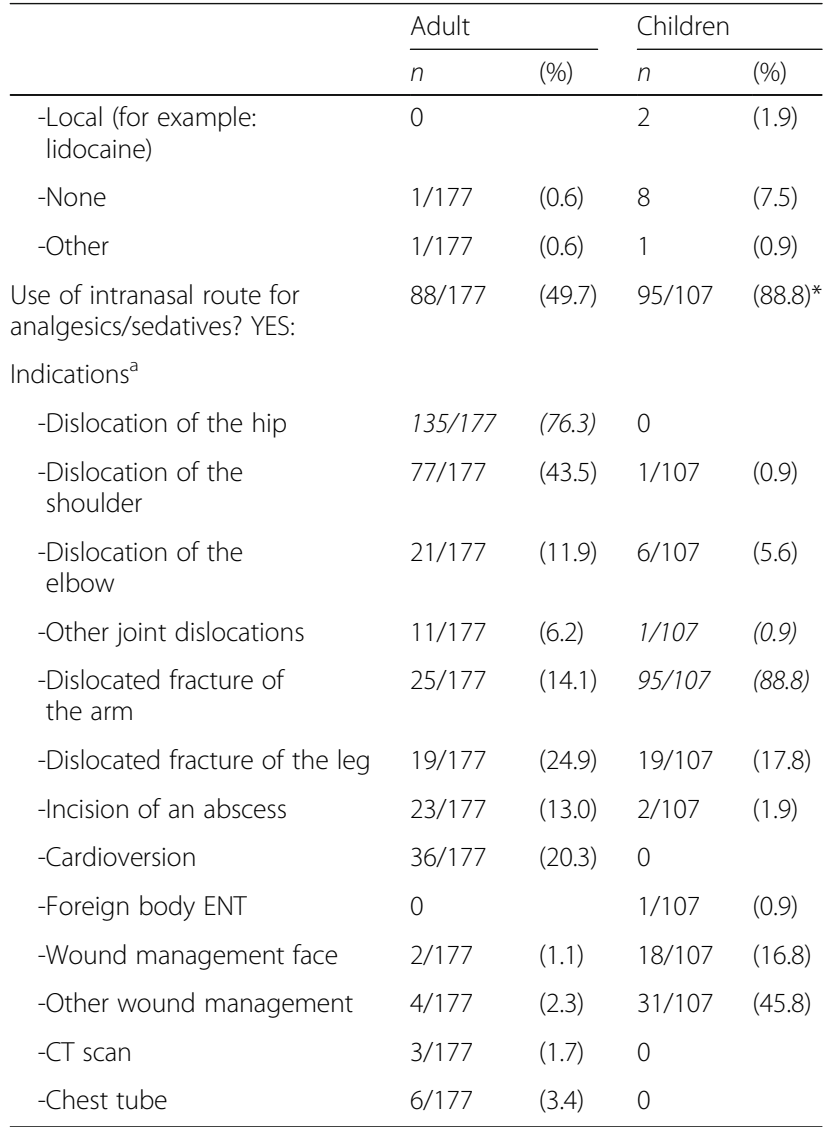

${ }^{a}$ Multiple answers possible

$E M$ emergency medicine, PSA procedural sedation and analgesia, ED emergency department, $C T$ computed tomography, ENT ear nose throat ${ }^{*} p<0.001$

for the paediatric population, this frequency was reached by $19.6 \%$ (21/107). The performance rate for adult PSA was declared sufficient to maintain skill-competency by 75.7\% (134/177), and for paediatric PSA, the rate was deemed sufficient by $54.2 \%$ (58/107). The most common reason for not performing PSA in adults was the absence of additional EPs in the ED to cover other ED patient care. The most common reason given for not performing paediatric PSA in the ED was lack of experience to perform paediatric PSA.

PSA training during and after residency

The training received in paediatric PSA was significantly lower than PSA in adults $(p<0.05)$ (Table 2). Only 40 of 181 (22\%) EPs received paediatric PSA training, and of those who received training, only $30.0 \%(12 / 40)$ believed it to be sufficient (Table 1). Lack of significant exposure to due to the short duration of the 3-year residency-training program was considered one of the major causes for this insufficiency. The PSA training provided by NSEP had been attended by $46.4 \%$ of the respondents. The desire to 
Table 2 Survey on adult and paediatric PSA training within the Dutch EM training program

\begin{tabular}{|c|c|c|c|c|}
\hline & \multicolumn{2}{|l|}{ Adults } & \multicolumn{2}{|c|}{ Children } \\
\hline & $n$ & $(\%)$ & $n$ & $(\%)$ \\
\hline $\begin{array}{l}\text { Were you trained in PSA } \\
\text { during your EM training } \\
\text { program? YES: }\end{array}$ & $112 / 181$ & (61.9) & $40 / 181$ & $(22.1)^{*}$ \\
\hline $\begin{array}{l}\text { Was the PSA training } \\
\text { during your EM training } \\
\text { program sufficient? YES: }\end{array}$ & $46 / 112$ & $(41.1)$ & $12 / 40$ & $(30.0)$ \\
\hline \multicolumn{5}{|l|}{$\begin{array}{l}\text { What was the reason for } \\
\text { this insufficient training? }\end{array}$} \\
\hline $\begin{array}{l}\text {-Lack of exposure due } \\
\text { to a short ( } 3 \text { years) EM } \\
\text { training program }\end{array}$ & $28 / 66$ & $(42.4)$ & $20 / 28$ & (71.4) \\
\hline $\begin{array}{l}\text {-Lack of exposure due } \\
\text { to competition with other } \\
\text { specialties }\end{array}$ & $4 / 66$ & $(6.1)$ & $1 / 28$ & (3.6) \\
\hline $\begin{array}{l}\text {-Insufficient training } \\
\text { because mentors did not } \\
\text { perform PSA }\end{array}$ & $20 / 66$ & (30.3) & $8 / 28$ & (28.6) \\
\hline $\begin{array}{l}\text {-Insufficient airway } \\
\text { management skills } \\
\text { training }\end{array}$ & $4 / 66$ & $(6.1)$ & $2 / 28$ & $(7.1)$ \\
\hline
\end{tabular}

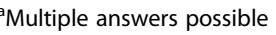

$E M$ emergency medicine, PSA procedural sedation and analgesia ${ }^{*} p<0.05$

continue vocational training was expressed by $50.3 \%$. The vocational training with the highest demand was paediatric PSA training $74.7 \%(68 / 91)$.

\section{Quality: guideline use and quality indicators}

Almost all EPs 98.3\% have knowledge of the national guideline on PSA and frequently use it as their default protocol (81.5\%). The NSEP practical emergency PSA guideline was used slightly more frequently $87.5 \%$ (147/ 168). PSA procedures were registered by $99.4 \%$ either on paper $(61.3 \%)$ or in an electronic patient record $(38.1 \%)$. PSA-related adverse event registration, in accordance with the quality standard set by the NSEP, was met according to $98.3 \%$. First choices of PSA sedatives and analgesics are displayed in Table 1.

\section{Self-reflection on competencies regarding PSA}

EPs reflected on their PSA competencies in both adult and paediatric PSA (Tables 3 and 4). The EPs were queried on their capabilities and competencies in performing PSA and if they were able to perform advanced life support (ALS)/advanced paediatric life support (APLS) appropriately. They agreed significantly stronger $(p<0.001)$ when reflecting their PSA competencies in adults compared to paediatric patients. This effect was not altered by age, years of registration, or work experience of the EP.
Table 3 Self-reflection of emergency physicians on adult PSA in The Netherlands $(n=177)$

\begin{tabular}{|c|c|c|c|c|c|c|c|c|c|c|}
\hline & \multicolumn{2}{|c|}{$\begin{array}{l}\text { Strongly } \\
\text { agree }\end{array}$} & \multicolumn{2}{|c|}{ Agree } & \multicolumn{2}{|c|}{ Neutral } & \multicolumn{2}{|c|}{ Disagree } & \multicolumn{2}{|c|}{$\begin{array}{l}\text { Strongly } \\
\text { disagree }\end{array}$} \\
\hline & $\bar{n}$ & (\%) & $\bar{n}$ & $(\%)$ & $\bar{n}$ & (\%) & $n$ & (\%) & $n$ & (\%) \\
\hline $\begin{array}{l}\text { I am capable and } \\
\text { competent in } \\
\text { performing PSA in } \\
\text { adults }\end{array}$ & 101 & $(57.1)$ & 70 & $(39.5)$ & 4 & (2.3) & 2 & (1.1) & 0 & $(0.0)$ \\
\hline $\begin{array}{l}\text { I am able to } \\
\text { perform ALS } \\
\text { appropriately }\end{array}$ & 151 & (85.3) & 26 & $(14.7)$ & 0 & $(0.0)$ & 0 & $(0.0)$ & 0 & (0.0) \\
\hline $\begin{array}{l}\text { I am aware of } \\
\text { the (contra-) } \\
\text { indications and } \\
\text { precautions for } \\
\text { PSA }\end{array}$ & 115 & $(65.0)$ & 61 & $(34.5)$ & 1 & $(0.5)$ & 0 & $(0.0)$ & 0 & $(0.0)$ \\
\hline $\begin{array}{l}\text { I am able to } \\
\text { recognize and } \\
\text { treat the most } \\
\text { common adverse } \\
\text { events and/or } \\
\text { complications }\end{array}$ & 102 & $(57.6)$ & 72 & $(40.7)$ & 3 & (1.7) & 0 & $(0.0)$ & 0 & $(0.0)$ \\
\hline
\end{tabular}

\section{Discussion}

The present study provides insight into the current PSA practice and competences of Dutch EPs in both adult and paediatric patients. First, nearly all EPs (97.8\%) performed PSA in adult patients, compared to only $59.1 \%$ who performed PSA in paediatric patients. Second, self-reflection indicated that EPs felt less competent in performing paediatric PSA when compared to adult PSA. Consequently, there is a significant gap between adult and paediatric PSA performance by EPs in Dutch EDs. The most common reason for not performing paediatric PSA according to the EPs was the lack of exposure due to the relatively short 3-year training program.

Other countries report similar gaps between adult and paediatric PSA in the ED [13, 14]. McCoy et al. addressed the challenges of practice and provision of paediatric PSA in the UK and Ireland. They concluded that among others that lack of formal training and a lack of recognition of PSA as a specialised EM skill contributed to the difficulties to provide paediatric PSA in the ED [13]. The unavailability of PSA around-the-clock for both the adult and paediatric populations in Dutch EDs is another concern. As shown in the results, EPs appear to be the foremost providers of PSA in the ED for both adult and paediatric patients. Currently, only $20.7 \%$ of the 87 EDs have 24/7-coverage by EPs. Increase of EP staff could therefore may be an effective step in reaching good quality emergency PSA service for all ED patients at all times. An additional positive side-effect may be further reduction of healthcare costs as ED sedation 
Table 4 Self-reflection of emergency physicians on paediatric PSA in The Netherlands $(n=107)$

\begin{tabular}{|c|c|c|c|c|c|c|c|c|c|c|}
\hline & \multicolumn{2}{|c|}{ Strongly Ag agree } & \multicolumn{2}{|c|}{ Agree } & \multicolumn{2}{|c|}{ Neutral } & \multicolumn{2}{|c|}{ Disagree } & \multicolumn{2}{|c|}{ Strongly disagree } \\
\hline & $n$ & (\%) & $n$ & $(\%)$ & $n$ & $(\%)$ & $n$ & (\%) & $n$ & $(\%)$ \\
\hline I am capable and competent in performing paediatric PSA & 33 & $(30.9)$ & 61 & $(57.0)$ & 10 & $(9.3)$ & 3 & $(2.8)$ & 0 & $(0.0)$ \\
\hline I am able to perform APLS appropriately & 60 & $(56.1)$ & 46 & $(43.0)$ & 1 & $(0.9)$ & 0 & $(0.0)$ & 0 & $(0.0)$ \\
\hline $\begin{array}{l}\text { I am able to inform the patient, parents and/or a legal } \\
\text { guardian about the sedation technique, the effects, possible } \\
\text { adverse events and alternatives }\end{array}$ & 59 & $(55.2)$ & 47 & $(43.9)$ & 1 & $(0.9)$ & 0 & $(0.0)$ & 0 & $(0.0)$ \\
\hline $\begin{array}{l}\text { I can guarantee paediatric friendly circumstances before, } \\
\text { during and after the procedure }\end{array}$ & 32 & $(30.0)$ & 57 & $(53.2)$ & 17 & $(15.9)$ & 1 & $(0.9)$ & 0 & $(0.0)$ \\
\hline $\begin{array}{l}\text { I am able to effectively use local or topical anaesthesia } \\
\text { when needed }\end{array}$ & 55 & $(51.4)$ & 48 & $(44.9)$ & 4 & $(3.7)$ & 0 & $(0.0)$ & 0 & $(0.0)$ \\
\hline The age of the patient determines if I perform PSA or not & 19 & $(17.8)$ & 54 & $(50.4)$ & 11 & $(10.3)$ & 20 & (18.7) & 3 & $(2.8)$ \\
\hline $\begin{array}{l}\text { I only apply PSA in paediatric patients in the direct presence } \\
\text { of another specialist }\end{array}$ & 0 & $(0.0)$ & 7 & (6.5) & 9 & (8.4) & 52 & (48.6) & 39 & (36.5) \\
\hline $\begin{array}{l}\text { I only apply PSA in paediatric patients after consulting an } \\
\text { anaesthesiologist/paediatrician. }\end{array}$ & 0 & $(0.0)$ & 2 & (1.9) & 4 & (3.7) & 58 & (54.2) & 43 & $(40.2)$ \\
\hline
\end{tabular}

APLS advanced paediatric life support, PSA procedural sedation and analgesia

has shown to offer considerable savings, compared with theater-based management [6].

The second aim was to investigate the competencies of Dutch EPs in both adult and paediatric PSA. To our knowledge, this is the first cross-sectional study on a national level amongst EPs demonstrating their selfreflection on PSA-related skills. We would like to stress that because there is a lack in confidence to perform paediatric PSA, this does not automatically imply that the PSA provided is of a lesser quality. Multiple Dutch studies have shown that EPs can perform safe and effective PSA, and they have similar adverse event rates when compared their international counterparts $[5,7,15]$. However, this lack in confidence does result in fewer EPs performing paediatric sedations in the ED, resulting in less skill maintenance and less exposure for the EPs in training. Moreover, this causes a potential serious risk for under treatment of pain in the paediatric ED population.

According to the respondents, the root cause of this observed difference between adult and paediatric PSA appears to be due to the lack of exposure of paediatric PSA during the relatively short 3-year training program in The Netherlands. A 3-year training program may be considered short when compared to the 5-year European standard [16-18]. When PSA by EPs was implemented, it usually commenced with adult PSA and then slowly progressed to paediatric PSA. However, in some of these pioneering EDs, paediatric PSA was restricted to be performed by anaesthesiologists and/or paediatricians, making it more difficult for these EPs to obtain sufficient training and exposure. Furthermore, countries where paediatric EM is a recognised sub-specialty of EM offer specific training during or after completion of the EM residency program. For example, in the UK, the training consists of 6 months in a paediatric ED approved for sub-specialty training and 6 months of ward-based paediatrics of which 3 months should be in the care of unconscious and critically ill children, such as in a paediatric ICU. Secondary to both low-volume EDs in the Netherlands (15,000-50,000 patients/year) and excellent general practitioner (GP) care, there is insufficient exposure to seriously ill paediatric patients in a 3-year time frame. This lack of exposure is further intensified by the strict Dutch Labour Law, which limits working hours up to a maximum of 48 per week including education hours [18]. Extending the training program in general or adding a PSA-fellowship to the training program with specific targets on both adult and paediatric PSA skills could aid the next generation of EPs. To close this gap, PSA training is since 2014 mandatory for all residency training programs in the country. Although this implementation may have a positive influence, it is not specified in the current curriculum that these PSA skills should be acquired to the same extent for both adult and paediatric patients. In addition, we believe not all EP mentors are currently competent to train the new generation of EPs because their training was before 2014. Before 2014, EM residency-training programs did not have a uniform approach in teaching PSA. Therefore, simultaneous implementation of mandatory vocational paediatric PSA training and credentialing like with annual online courses and practical recertification classes will be essential to achieve competency of paediatric PSA by all EPs.

We acknowledge that there are several limitations of this study. The response rate of $41.3 \%$ makes this a limited sample. However, the respondents represented 84.6\% (55/65) hospitals with EPs on their staff. Therefore, we think our results are generally representative for PSA activities throughout the country. Since this study 
was aimed at EPs, we cannot draw any conclusions about PSA performance and guideline adherence in EDs without EPs. As with every survey, there is a significant risk for responder bias. We aimed to address this bias by guaranteeing anonymity and confidentiality of all individual survey data.

\section{Conclusions}

This nationwide survey demonstrates that there is still a significant gap between the performance of adult and paediatric PSA in the ED even though PSA-related training, guideline adherence, and registration of PSA-related adverse events appear to be adequate. Enhancement of paediatric PSA training during and after the residency program in combination with an increase of EP-staff can help improve the availability of both adult and paediatric PSA in the ED. This may further improve the overall quality of ED-pain management.

\section{Additional file}

Additional file 1: Procedural sedation survey for Dutch emergency physicians. (PDF $102 \mathrm{~kb}$ )

\section{Abbreviation}

EM: Emergency department; EP: Emergency physicians; PSA: procedural sedation and analgesia

\section{Acknowledgements}

The authors would like to thank The Netherlands Society of Emergency Physicians for their valuable contribution. We thank Dr. Ellen Tromp, clinical epidemiologist, for her helpful contribution to the statistical analysis.

\section{Funding}

No funding.

\section{Availability of data and materials}

The datasets used or analyzed during the current study are available from the corresponding author upon reasonable request.

\section{Authors' contributions}

MK and GS conceived the study. MK and SV acquired and managed the data. MK, SV, and GS analyzed and interpreted the data. MK drafted the manuscript. MK, GS, WT, and FP contributed substantially to its revisions. MK and FP take responsibility for the paper as a whole. All authors read and approved the final manuscript.

\section{Authors' information}

MK is an EP and PhD candidate at University of Amsterdam. GS is an EP and PhD candidate at University of Eindhoven. SV is a medical student. WT is an EP with a PhD. FP is a paediatrician with a PhD and senior researcher.

\section{Ethics approval and consent to participate}

Approval for this study was obtained through the Scientific Review Committee of the Tergooi Hospital. The committee granted further review board exemption.

\section{Competing interests}

The authors declare that they have no competing interests.

\section{Publisher's Note}

Springer Nature remains neutral with regard to jurisdictional claims in published maps and institutional affiliations.

\section{Author details}

${ }^{1}$ Academic Medical Centre/ University of Amsterdam, Amsterdam, The Netherlands. ${ }^{2}$ Emergency Department, Catharina Hospital, Eindhoven, The Netherlands. ${ }^{3} \mathrm{~V} U$ University Medical Center, Amsterdam, The Netherlands. ${ }^{4}$ Emergency Department, Catharina Hospital, Eindhoven, The Netherlands. ${ }^{5}$ Department of Pediatrics, Tergooi Hospital, Blaricum, The Netherlands.

${ }^{6}$ Tergooi Hosptial, Hilversum, The Netherlands.

Received: 5 April 2017 Accepted: 20 November 2017

Published online: 15 December 2017

\section{References}

1. Elkhodair SM, Baker EC, Glasebrook WR, Pott JD, Freund Y, Harrris TR. Emergency department procedural sedation: the London experience. Eur J Emerg Med. 2015;22(6):407-12. doi: 10.1097/MEJ.0000000000000197.

2. Green RS, Butler MB, Campbell SG, Erdogan M. Adverse events and outcomes of procedural sedation and analgesia in major trauma patients. J Emerg Trauma Shock. 2015;8(4):210-5. doi: 10.4103/0974-2700.166612.

3. Salleeh HMB, Al Ahmadi T, Mujawar Q. Procedural sedation for pediatric patients in the Emergency Department at King Khalid University Hospital, Riyadh. KSA J Emerg Trauma Shock. 2014;7(3):186-9. doi: 10. 4103/0974-2700.136862

4. Pitetti RD, Singh S, Pierce MC. Safe and efficacious use of procedural sedation and analgesia by non-anesthesiologists in a pediatric emergency department. Arch Pediatr Adolesc Med. 2003;157(11):1090-6.

5. Smits GJ, Kuypers MI, Mignot L, Reijners EPJ, Oskam E, Van Doorn K, Thijssen WAMH, Korsten EHM. Procedural sedation in the emergency department by Dutch emergency physicians: a prospective multi-center observational study of 1711 adults. Emerg Med J. 2016; doi: 10.1136/emermed-2016-205767 Published Online First

6. Boyle A, Dixon V, Fenu E, Heinz P. Sedation of children in the emergency department for short painful procedures compared with theatre, how much does it save? Economic evaluation. Emerg Med J. 2011;28:383-6.

7. Kuypers MI, Mencl F, Verhagen MF, Kok MF, Dijksman LM, Simons MP. Safety and efficacy of procedural sedation with propofol in a country with a young emergency medicine training program. Eur J Emerg Med. 2011;18(3): 162-6. doi: 10.1097/MEJ.0b013e32834230fb7a.

8. Kuypers M, Plötz FB, Mencl F. Implementation of procedural sedation in the emergency department. Int J Emerg Med. 2017;10:6. doi: 10.1186/s12245-017-0130-2.

9. Dutch institute for healthcare improvement (CBO). Richtlijn sedatie en of analgesie (PSA) op locaties buiten de operatiekamer. CBO 2012;1-343.

10. Netherlands Society of Emergency Medicine. Handreiking Procedurele Sedatie en Analgesie door SEH-artsen op de Spoed Eisende Hulp. https://www.nvsha. nl/files/33/NVSHA_Richtlijn_PSA_versie_2.0.pdf. Accessed 22 Dec 2016.

11. Koning SW, Gaakeer MI, Veugelers R. Three-year emergency medicine training program in The Netherlands: first evaluation from the residents' perspective. Int J Emerg Med. 2013;6(1):30. doi: 10.1186/1865-1380-6-30.

12. von Elm E, Altman DG, Egger M, Pocock SJ, Gøtzsche PC, Vandenbroucke JP. The Strengthening the Reporting of Observational Studies in Epidemiology (STROBE) statement: guidelines for reporting observational studies. J Clin Epidemiol. 2008;61:344-9.

13. McCoy S, Lyttle MD, Hartshorn S, Larkin P, Brenner M, O'Sullivan R. A qualitative study of the barriers to procedural sedation practices in paediatric emergency medicine in the UK and Ireland. Emerg Med J. 2016; 33:527-32. https://doi.org/10.1136/emermed-2015-205418.

14. Krauss BS, Green SM. Procedural sedation and its place in paediatric emergency medicine. Emerg Med J. 2016;33(8):525-6. https://doi.org/10. 1136/emermed-2016-205743.

15. Leroy PL, Gorzeman MP, Sury MR. Procedural sedation and analgesia in children by non-anesthesiologists in an emergency department. Minerva Pediatr. 2009 Apr;61(2):193-215.

16. Petrino R. European curriculum for emergency medicine. Eur J Emerg Med. 2009:16(3):113-4. doi: 10.1097/MEJ.0b013e32832b0239.

17. Council Directive. 2006/100/EC. 2006/100/EC.

18. Gaakeer MI, van den Brand CL, Bracey A, Lieshout JM, Patka P. Emergency medicine training in the Netherlands, essential changes needed. Int J Emerg Med. 2013;6:19. doi: 10.1186/1865-1380-6-19. 